\title{
REMOTE BRAINSTORMING: METHODOLOGICAL INTERVENTIONS IN DESIGNING FROM A DISTANCE
}

\author{
Domingo, Lawrence (1); \\ Gutzeit, Marius (2,1); \\ Leifer, Larry (1); \\ Auernhammer, Jan Michel Kurt (1) \\ 1: Stanford University; \\ 2: Karlsruhe Institute of Technology
}

\begin{abstract}
This paper examines the immediate effects of group methods in facilitating remote team collaboration. We recruited seven teams with prior experience working together. All teams completed two current, complex, and open-ended design challenges using remote tools. We examined design activities before and after teams were given a design method intervention. The interventions were a Brainstorming Method to promote divergent thinking and the Five-Whys method to promote analytical thinking. Using OpenFace, we observed changes in emotion by examining facial expressions. We found that the brainstorming intervention did not have a change in ideation performance and the problem analysis intervention had a decrease in ideation performance. Teams used digital media to facilitate communication but were constrained by the media's tools. Our results can inform teams in organizations interested in promoting divergent thinking to not expect immediate improvements in ideation performance following the introduction of a design method. Future research is required to identify relevant abilities and social skills needed to facilitate remote ideation through design methods.
\end{abstract}

Keywords: Creativity, Design methods, Collaborative design, Remote, Brainstorming

\section{Contact:}

Auernhammer, Jan Michel Kurt

Stanford University

Mechanical Engineering

United States of America

jan.auernhammer@stanford.edu 


\section{INTRODUCTION}

The COVID19 pandemic changed the way design and other teams had to work. Remote working became a primary mode for teams to interact and collaborate. Teams needed to adapt and find ways to productively work together through digital tools, such as video conferencing and online collaboration technologies. Digital tools constrain and influence team behavior and collaboration (McLuhan, 1964; Eris, 2003). In the past, many scholars investigated the impact of remote communication technologies on team dynamics and interactions. Hinds (2003) presented a taxonomy of remote work conflicts such as task conflicts, affective conflict, and process conflicts. Organizations could, for example, intervene to facilitate remote teamwork through process methods to reduce affective conflict. Jung (2011) found that in in-person teams, the way design teams managed their emotions affected how they managed conflict, which affected team performance. By facilitating remote team processes, organizations can potentially impact team performance in remotely located teams.

Team interactions and collaborative reasoning are often supported by group methods. Group creativity methods, such as Brainstorming, are commonly used techniques in design projects (Sutton and Hargadon, 1996). A look into Kumar's (2013) 101 Design Methods shows teams interacting in-person using various techniques. These methods aim to enable a particular team behavior and stimulate collective reasoning processes, such as divergent and convergent or creative and analytical thinking. Furthermore, research shows that emotions, gesturing, asking different types of questions, and sketching can influence and are part of the collaborative team interaction and creative design team performance (Tang, 1989; Eris, 2003; 2014; Jung, 2011). Design team research mainly investigated the use of methods and team interactions in in-person teams. We were interested in the effects of methods stimulating either creative or analytical thinking within team interactions in remote collaboration.

Understanding the influence of process facilitating methods, such as Brainstorming in remote teams, is important for teams in organizations to continuously solve creative problems and produce innovative solutions (Markman, 2020). The research presented in this paper examined the changes in team behavior (a) without a process method (pre-intervention) and (b) with a process method (postintervention) and compared the use of two common team methods: (i) Brainstorming Rules (creative thinking) and (ii) Five-Whys (analytical thinking).

\section{BACKGROUND}

Many researchers developed creative and problem-solving methods over the decades. For example, Zwicky (1949) developed Morphological Analysis for exploring multi-dimensional problems and solutions and non-quantified complex problems. In advertisement, Alex Osborn (1953) and his team developed the creative group method: Brainstorming. Brainstorming enables teams to come up with a higher number of good ideas by "deferring judgment" and "reach[ing] for quantity" (Osborn 1953). Cultivating these rules enhances individuals' ideation contributions within the team by promoting creative thinking. Osborn's (1953) Brainstorming rules are a frequently used method to encourage team behavior of psychological safety and freedoms, as suggested by Rogers (1954) and Arnold (1962), and collective divergent thinking, as outlined by Guilford (1950). Cultivating creative group techniques has been suggested to enable routine innovation in design consultancies (Sutton and Hargadon, 1996).

Like Brainstorming, methods to enable teams to comprehend complex problems have been developed in the Total Quality Movement. For example, Kaoru Ishikawa (1968) developed the Ishikawa diagram to enable teams to analyze the root cause of a complex problem situation. Each potential cause is traced back to identify a leading cause by asking, "Why?" five times. This method is part of the quality approach in the Toyota Production System (Ohno, 1988; Liker, 2004). Problem analysis techniques can break apart complex problems into more tangible problems that are easier to analyze and solve. Such methods stimulate analytical thinking in teams to solve complex problems.

Both methods aim to facilitate a different team mindset and behavior. The Brainstorming method aims to increase creative and divergent thinking and enable team behavior of open exchange. The Five-Why 
method aims to increase analytical thinking and enable team behavior of critically discussing the problem situation. Utilizing such methods can influence the problem-solving performance of teams. Both methods are relatively well-known and are easily adopted and used in remote team settings. Brainstorming and the Five-Why method is typically performed and examined in in-person meetings. Teams must productively work together through digital tools such as video conferencing or online collaboration tools. Some previous work (Eris, 2014; Sirkin, 2011) on distributed teamwork focused on dyads (team member-to-team member) or satellite- $\&$-hub (team-to-remote individual), respectively. Eris studied how distributed team members use gesturing and sketching to facilitate design communication when doing distributed work but did not study participants' emotional responses. Sirkin's work on remote collaboration focused on interactions with telepresent robots and collected data on the emotional responses of interacting team members. However, this work was not conducted at the individual team member level. Markman (2020) argued that organizations must get brainstorming right to solve the many challenges companies face during these times and suggests how to brainstorm remotely based on several theories. However, there is little research on creative or analytical techniques on team behavior and thinking in remote collaboration. Do such methods influence the reasoning and team behavior in remote teams? In this study, we were particularly interested in the methods' immediate impact and their different remote collaboration effects, including the production of ideas, behavior, and emotions.

\section{METHODOLOGY}

The study is designed to investigate the difference between team behavior, thinking, and performance influenced by group methods: (i) Brainstorming and (ii) Problem Analysis through an experiment. This study investigated teams who are not extensively trained in design methods to examine if these techniques will have an immediate effect on team creative performance.

\subsection{Group Composition}

This study recruited seven pre-formed teams of three team members with at least ten weeks of prior working experience. The prior working experience was necessary to minimize the dynamics of new team culture formation, such as forming roles and behavior norms. Table 1 summarizes the demographics data of the participating teams.

Table 1. Participant team demographics and assigned intervention

\begin{tabular}{|l|c|c|c|r|}
\hline $\begin{array}{l}\text { Gender } \\
\text { Diversity }\end{array}$ & $\begin{array}{c}\text { Agreement in } \\
\text { perceived } \\
\text { hierarchy }\end{array}$ & $\begin{array}{c}\text { Perceived } \\
\text { Hierarchy } \\
\text { Distance }\end{array}$ & $\begin{array}{c}\text { Toronto } \\
\text { Empathy } \\
\text { (Avg., St. Dev.) }\end{array}$ & $\begin{array}{r}\text { Intervention } \\
\text { (method prescribed) }\end{array}$ \\
\hline $3 \mathrm{M}$ & Agree & High & $47.00,2.65$ & Brainstorming \\
\hline $3 \mathrm{M}$ & Agree & Low & $47.33,0.58$ & Five-Whys \\
\hline $1 \mathrm{~F}, 2 \mathrm{M}$ & Agree & Low & $47.67,9.29$ & Brainstorming \\
\hline $3 \mathrm{M}$ & Agree & Medium & $42.67,5.69$ & Five-Whys \\
\hline $2 \mathrm{~F}, 1 \mathrm{M}$ & Disagree & $\begin{array}{c}\text { No Perceived } \\
\text { Distance }\end{array}$ & $51.33,1.53$ & Five-Whys \\
\hline $2 \mathrm{~F}, 1 \mathrm{M}$ & Disagree & $\begin{array}{c}\text { No Perceived } \\
\text { Distance }\end{array}$ & $52.67,5.13$ & Brainstorming \\
\hline $3 \mathrm{M}$ & Disagree & $\begin{array}{c}\text { No Perceived } \\
\text { Distance }\end{array}$ & $42.67,4.62$ & Five-Whys \\
\hline
\end{tabular}

Table 1 reports the diversity of the team gender composition and perceived hierarchy. Participants were between the ages of 18-34 years old. Each participant categorized themselves in relation to other 
members in terms of perceived hierarchical difference. There was no shared perception of hierarchy in three teams, while four teams had a shared agreement of the perceived hierarchy. High denotes that team members were on different levels of a perceived hierarchy. Low denotes that team members are perceived to be in an egalitarian team or on the same level of a perceived hierarchy.

\subsection{Experiment Design}

The experiment study followed the design research approach of 1) examine team interactions, 2) intervene by providing a group method, and 3) observe differences in design activity (e.g., Lewin 1946; Tang, 1989). Participants had to design for current, real, open, and complex design challenges. The global pandemic provided design challenges in which the problems are shared among all participants. The entire study was conducted using the remote collaboration digital video conferencing platform Zoom. Figure 1 outlines the experimental procedure.

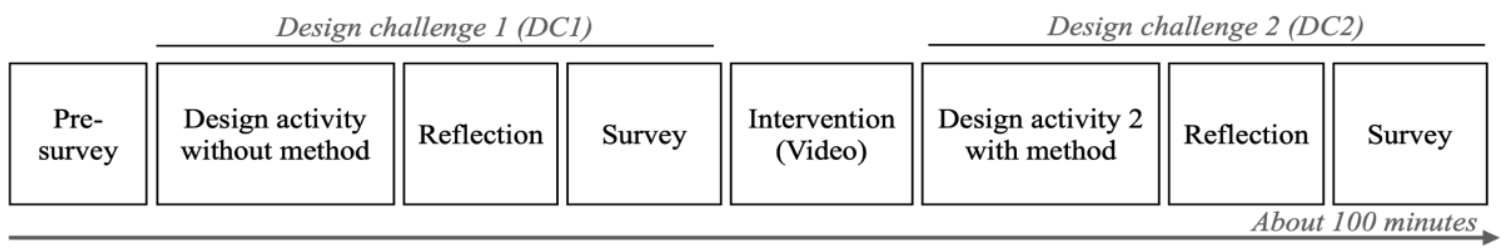

Figure 1. Experiment procedure timeline. A pre-survey was used to collect demographic information. A video intervention was administered between design challenge sessions.

\subsubsection{Pre-Survey}

Team members were given a demographics survey prior to the design challenges to assess group composition characteristics, including individual gender, self-esteem, empathy, shared work experience and perceived hierarchical structure.

\subsubsection{Design Challenge 1 (DC1) - without a method}

Design challenge sessions were 15 minutes in length. The first design challenge helped serve as a preintervention control for comparison. Participating teams had to ideate solutions for the following design challenge problem prompt:

Design Prompt 1: Protection of people from infections

"Airborne viruses spread from person to person, mainly in droplets from when someone coughs or sneezes. Tiny droplets from a sick person move through the air and land on the mouths or noses of others nearby. People can also become infected by touching their faces and eyes. This is an unconscious process in which people touch their faces many times per day. Design a solution that will prevent people from infecting each other and themselves."

Following each design challenge, participants were given a semi-structured interview and surveyed. The interview included mapping out their experience, salient events, and emotional state on an outlined journey map. Interviews were followed by a survey that captured self-esteem and psychological safety (not reported in this paper and will be published elsewhere).

\subsubsection{Intervention}

Teams were randomly assigned either a Brainstorming or Problem Analysis intervention, which was presented as a two-minute recorded video. Participants were then given the second design challenge immediately after the video tutorial on the process method. Teams were not asked explicitly to use the method to let behavior occur naturally.

\subsubsection{Design Challenge 2 (DC2) - with a method}

The procedure from DC1 was repeated in design challenge 2 (DC2) post-intervention with the following different problem prompt:

Design Prompt 2: Saving lives in resources shortage 
"Due to the tremendous increase in infected people, hospital resources have become limited. The development time to produce more hospital resources exceeds the mortality risk of sick patients. This leads to medical staff needing to decide whose life to save. Design a solution that saves lives in the short term."

\subsection{Data Collection}

Survey data was collected via Qualtrics. Video and audio data about team behavior and interaction was captured in password-protected Zoom video call sessions, and individual reflections of the design activities were done in semi-structured interviews directly after the design activities. We asked participants to leave their video camera on and limit their interactions to one screen with the proper camera hardware to capture their facial expressions for Open Face analysis.

\subsection{Data Analysis}

We analyzed the video, audio, and questionnaire data to examine both team behavior and team performance. To answer the impact on methods on team interactions in remote collaboration, we examined emotional expressions to identify engagement and conflict, word count to identify team member contribution, and idea produced to identify creative team performance.

\subsubsection{OpenFace - Emotional Expression}

We examined emotional behavior changes through facial micro-expressions using OpenFace 2.0 facial behavior analysis toolkit (Baltrušaitis et al., 2018; Ekman and Friesen, 1978). We tracked individual facial action units (AU) from the individual participants' video streams extracted from the recorded video calls. We applied a weighted average resampling as well as a minimum-maximum scaler to normalize. For measuring positive expressions, we tracked both AU6, which indicates raising of the cheeks, and AU12, which indicates pulling up of the lip corners (Chikersal et al., 2017). We applied a threshold of 0.3 to filter the expression of positive emotion from any noise during the individual participants' design challenge videos.

\subsubsection{Transcript and Video Analysis}

The design activity sessions were transcribed for further analysis. Transcripts in tandem with the videos were used to codify ideas. Transcripts captured speaker turns and content. Using Adams's model of fluency and flexibility for assessing idea generation, we counted the total number of ideas expressed by a team and the total number of layers a team used to expand on ideas. A new idea root was generated when the team presented a new ideation theme and could model the team's flexibility. A new idea layer was generated when a new feature was explicitly expressed by a team member on a preceding idea and captured team fluency. More detailed features would be nested within subsequent levels of layers which indicated the depth of idea exploration. Transcript coding was corroborated using the raw video footage to clean any misassigned speaker attributions. We then counted the number of words spoken by each team member to quantify speaker interaction dynamics. The authors also noted key behavior differences such as the use of non-audio media in the remote sessions and discussed the differences compared to in-person design task settings.

This analysis allowed us to examine the active enactment of the intervention method (i.e., Brainstorming Rules or Five-Whys). In the Problem Analysis (Five-Whys) cohort, only one team did not actively apply the method intervention.

\section{FINDINGS}

The data analysis revealed several differences in team behavior and performance.

\subsection{Team Behavior Data}

\subsubsection{Team Behavior: Word Counts}

Table 2 shows the number of words spoken by each team for both sessions. Transcripts were cleaned for proper speaker assignment, and words were counted for each speaker. The percentages for each speaker are captured in Table 3. Tables 2 and 3 indicate that the Brainstorming method intervention 
did not change team behavior much, and the Five-Why method intervention had different results. The total number of words spoken in both conditions had no change in statistical significance for a paired t-test $(B S p$-value $=0.22$, PA p-value $=0.25)$. Note that a team member from Team 7 dropped from the second design session during the last 3 minutes of the call. All necessary surveys and interviews were still conducted for data collection.

Table 2. The total number of words spoken by each team for both design activities.

\begin{tabular}{|l|c|c|c|r|}
\hline Teams & Group method & $\begin{array}{c}\text { Design Challenge 1 } \\
\text { (without a method) }\end{array}$ & $\begin{array}{c}\text { Design Challenge 2 } \\
\text { (with a method) }\end{array}$ & General Observation \\
\hline 1 & Brainstorming & 2512 & 2494 & No change \\
\hline 3 & Brainstorming & 1723 & 1460 & Decrease \\
\hline 6 & Brainstorming & 1814 & 1715 & No change \\
\hline 2 & $\begin{array}{c}\text { Five-Whys } \\
\text { (not performed) }\end{array}$ & 1684 & 1830 & Decrease \\
\hline 4 & Five-Whys & 2362 & 1981 & Decrease \\
\hline 5 & Five-Whys & 2242 & 2012 & Decrease \\
\hline 7 & Five-Whys & 1903 & 1736 & \\
\hline
\end{tabular}

Table 3. Percentage of words spoken by each individual.

\begin{tabular}{|l|c|c|c|c|c|c|c|r|}
\hline \multirow{2}{*}{ Teams } & \multirow{2}{*}{ Group method } & \multicolumn{3}{|c|}{$\begin{array}{c}\text { Design Challenge 1, } \\
\text { w/o a method (\%) }\end{array}$} & \multicolumn{2}{|c|}{$\begin{array}{c}\text { Design Challenge 2, } \\
\text { with a method (\%) }\end{array}$} & $\begin{array}{r}\text { Difference in distribution of } \\
\text { spoken words among team } \\
\text { members }\end{array}$ \\
\cline { 3 - 8 } & & A & B & C & A & B & C & No change; Equal \\
\hline 1 & Brainstorming & 38.14 & 29.82 & 32.05 & 37.01 & 38.85 & 24.14 & $\begin{array}{r}\text { No change; single-member } \\
\text { dominating the discussion }\end{array}$ \\
\hline 3 & Brainstorming & 17.41 & 25.94 & 56.65 & 12.81 & 14.59 & 72.60 & $\begin{array}{r}\text { No change; slightly led by } \\
\text { one individual }\end{array}$ \\
\hline 6 & Brainstorming & 43.38 & 27.67 & 28.94 & 42.39 & 33.24 & 24.37 & $\begin{array}{r}\text { Change towards equal } \\
\text { distribution }\end{array}$ \\
\hline 4 & $\begin{array}{c}\text { Five-Whys } \\
\text { (not performed) }\end{array}$ & 15.14 & 31.35 & 53.50 & 29.62 & 31.58 & 38.80 & No change \\
\hline 5 & Five-Whys & 49.24 & 23.96 & 26.80 & 42.45 & 34.48 & 23.07 & $\begin{array}{r}\text { From equal to two-member } \\
\text { discussion }\end{array}$ \\
\hline 7 & Five-Whys & 31.49 & 34.88 & 33.63 & 10.34 & 45.87 & 43.79 & $\begin{array}{r}* * \text { Team member C dropped } \\
\text { from the call during the last } \\
3 \text { minutes of the design } \\
\text { challenge. }\end{array}$ \\
\hline
\end{tabular}

\subsubsection{Team Behavior: Emotional Expressions}

Tables 4 and 5 show the facial action unit of each participant's positive (happy) facial expressions and negative (sad) facial expressions. The Brainstorming teams decreased in positive emotion, while the Five-Why groups had no change to a slight increase in positive emotion. Paired t-tests were used to analyze both conditions before and after the intervention. However, there was no statistically significant change in happy facial expression for both conditions (BS $p=0.11, \mathrm{PA}, \mathrm{p}=0.13$ ). There was no statistically significant change in sad facial expression for both conditions (BS p=0.68, PA, $p=$ $0.84)$. Note that a team member from Team 7 dropped from the second design session during the last 3 minutes of the call. All necessary surveys and interviews were still conducted for data collection. 
Table 4. Positive emotion in percent (\%) of the total time of the design activities (measured through facial expressions unit) for brainstorming and problem analysis teams.

\begin{tabular}{|c|c|c|c|c|c|c|c|c|}
\hline \multirow[t]{2}{*}{ Teams } & \multirow{2}{*}{ Group method } & \multicolumn{3}{|c|}{$\begin{array}{c}\text { Design Challenge } 1 \text {, } \\
\text { without a method }\end{array}$} & \multicolumn{3}{|c|}{$\begin{array}{c}\text { Design Challenge } 2, \\
\text { with a method }\end{array}$} & \multirow{2}{*}{$\begin{array}{c}\text { Difference in } \\
\text { positive emotion }\end{array}$} \\
\hline & & A & B & $\mathrm{C}$ & A & B & C & \\
\hline 1 & Brainstorming & 2.34 & 4.65 & 10.27 & 1.92 & 1.71 & 2.77 & $\begin{array}{r}\text { DC1: } 52, \text { DC2: } 19 \\
\text { Decrease: } 33 \mathrm{sec}\end{array}$ \\
\hline 3 & Brainstorming & 10.05 & 18.62 & 20.21 & 5.88 & 6.20 & 16.23 & $\begin{array}{r}\text { DC1: 147, DC2: } 85 \\
\text { Decrease: } 62 \mathrm{sec}\end{array}$ \\
\hline 6 & Brainstorming & 6.17 & 10.77 & 34.79 & 17.62 & 3.11 & 7.52 & \begin{tabular}{|r|} 
DC1: 155, DC2: 85 \\
Decrease: $70 \mathrm{sec}$ \\
\end{tabular} \\
\hline 2 & $\begin{array}{c}\text { Five-Whys } \\
\text { (not performed) }\end{array}$ & 15.34 & 37.70 & 51.05 & 10.01 & 24.42 & 27.79 & $\begin{array}{r}\text { DC1: 312,DC2: } 187 \\
\text { Decrease: } 126 \mathrm{sec} \\
\end{array}$ \\
\hline 4 & Five-Whys & 11.89 & 20.22 & 14.27 & 13.52 & 20.07 & 14.61 & $\begin{array}{r}\text { DC1: 139, DC2:145 } \\
\text { Increase: } 6 \mathrm{sec} \\
\end{array}$ \\
\hline 5 & Five-Whys & 5.96 & 6.18 & 3.94 & 3.06 & 5.32 & 1.67 & $\begin{array}{r}\mathrm{DC} 1: 5, \mathrm{DC} 2: 3 \\
\text { No change } \\
\end{array}$ \\
\hline 7 & Five-Whys & 9.23 & 6.09 & 14.01 & 9.73 & 9.89 & 13.4 & $\begin{array}{r}\text { DC1: } 88, \mathrm{DC} 2: 99 \\
\text { Increase: } 11 \mathrm{sec}\end{array}$ \\
\hline
\end{tabular}

Table 5. Negative emotion in percent (\%) of the total time of the design activities (measured through facial expressions unit) for brainstorming and problem analysis teams.

\begin{tabular}{|c|c|c|c|c|c|c|c|c|}
\hline \multirow[t]{2}{*}{ Teams } & \multirow[t]{2}{*}{ Group method } & \multicolumn{3}{|c|}{$\begin{array}{c}\text { Design Challenge } 1, \\
\text { without a method }\end{array}$} & \multicolumn{3}{|c|}{$\begin{array}{c}\text { Design Challenge } 2, \\
\text { with a method }\end{array}$} & \multirow{2}{*}{$\begin{array}{r}\text { Difference in } \\
\text { negative emotion }\end{array}$} \\
\hline & & $\mathrm{A}$ & B & $\mathrm{C}$ & A & B & $\mathrm{C}$ & \\
\hline 1 & Brainstorming & 27.6 & 3.9 & 28.2 & 30.3 & 11.2 & 12.6 & $\begin{array}{r}\text { DC1: 179, DC2: } 162 \\
\text { Decrease: } 17 \mathrm{sec}\end{array}$ \\
\hline 3 & Brainstorming & 28.5 & 25.1 & 41.1 & 9.5 & 31.3 & 67.8 & $\begin{array}{r}\text { DC1: } 284, \mathrm{DC} 2: 326 \\
\text { Increase: } 42 \mathrm{sec}\end{array}$ \\
\hline 6 & Brainstorming & 67.8 & 7.1 & 30.0 & 30.5 & 11.9 & 30.0 & $\begin{array}{r}\text { DC1: } 318, \text { DC2: } 226 \\
\text { Decrease: } 92 \mathrm{sec}\end{array}$ \\
\hline 2 & $\begin{array}{c}\text { Five-Whys } \\
\text { (not performed) }\end{array}$ & 8.9 & 25.3 & 7.1 & 8.4 & 15.4 & 5.3 & $\begin{array}{r}\text { DC1: } 124, \text { DC2: } 87 \\
\text { Decrease: } 37 \mathrm{sec} \\
\end{array}$ \\
\hline 4 & Five-Whys & 23.1 & 15.8 & 13.5 & 37.4 & 14.8 & 7.5 & $\begin{array}{r}\text { DC1: } 157, \mathrm{DC} 2: 179 \\
\text { Increase: } 22 \mathrm{sec}\end{array}$ \\
\hline 5 & Five-Whys & 10.4 & 34.7 & 14.2 & 24.2 & 36.0 & 5.8 & $\begin{array}{r}\text { DC1: } 178, \mathrm{DC} 2: 198 \\
\text { Increase: } 20 \mathrm{sec}\end{array}$ \\
\hline 7 & Five-Whys & 25.2 & 16.4 & 8.0 & 13.4 & 21.9 & 6.5 & $\begin{array}{r}\text { DC1: } 149, \text { DC2: } 125 \\
\text { Decrease: } 23 \mathrm{sec}\end{array}$ \\
\hline
\end{tabular}

\subsection{Team Performance}

Table 6 reports the total number of ideas and idea layers for all teams. Table 7 reports the p-values for a paired t-test for both conditions. The Brainstorming teams had no statistically significant change in idea generation performance. However, the Problem Analysis teams had a statistically significant decrease in idea generation performance. 
Table 6. The number of ideas and number of idea layers generated by each team.

\begin{tabular}{|l|c|c|c|r|}
\hline $\begin{array}{l}\text { Brainstorming } \\
\text { teams }\end{array}$ & Group method & $\begin{array}{c}\text { Design Challenge 1 } \\
\text { (without a method) }\end{array}$ & $\begin{array}{c}\text { Design Challenge 2 } \\
\text { (with a method) }\end{array}$ & General Trend \\
\hline Team 1 & Brainstorming & 19 & 16 & Slight decrease \\
\hline Team 3 & Brainstorming & 13 & 16 & Slight increase \\
\hline Team 6 & Brainstorming & 14 & 18 & Slight increase \\
\hline Team 2 & Five-Whys & 22 & 13 & Decrease \\
\hline Team 4 & Five-Whys & 17 & 7 & Decrease \\
\hline Team 5 & Five-Whys & 22 & 10 & Decrease \\
\hline Team 7 & Five-Whys & 22 & 15 & Slight decrease \\
\hline
\end{tabular}

Table 7. Average number of ideas and idea layers with paired t-test statistical reports.

\begin{tabular}{|l|c|c|c|r|}
\hline & Intervention & $\begin{array}{c}\text { Design Challenge 1 } \\
\text { (without a method) }\end{array}$ & $\begin{array}{c}\text { Design Challenge 2 } \\
\text { (with a method) }\end{array}$ & $\begin{array}{r}\text { Paired t-test } \\
\text { (p-value) }\end{array}$ \\
\hline $\begin{array}{l}\text { Average } \\
\text { number } \\
\text { of Ideas }\end{array}$ & Brainstorming & 15.33 & 16.67 & 0.6039 \\
\cline { 2 - 5 } & Problem Analysis & 20.75 & 11.25 & 0.0028 \\
\hline $\begin{array}{l}\text { Average } \\
\text { number } \\
\text { of Layers }\end{array}$ & Brainstorming & 4.33 & 4.67 & 0.18503 \\
\cline { 2 - 5 } & Problem Analysis & 4.25 & 4.25 & 1.0 \\
\hline
\end{tabular}

Table 7 shows a statistically significant decrease in the Five Whys problem analysis method in teams' ideation performance following a problem analysis intervention in comparisons to DC1. Remote analysis teams produced fewer ideas and developed those ideas to a similar degree compared to preintervention without a method. In contrast, there was no change in the numbers of ideas produced in groups focused on creative thinking through Brainstorming.

\section{DISCUSSION AND IMPLICATIONS}

This study revealed new insights on the use of methods and their impact on team interaction in remote collaboration measured for each individual member. The findings show that the groups focused on creative and divergent thinking through remote brainstorming produced the same number of ideas before and after the intervention, spoke the same number of words, and decreased in expressed positive emotions. In comparison, the groups that focused on analytical and convergent thinking had a decrease in ideas and no change in expressed emotions. These main findings have several theoretical and practical implications discussed in more detail.

\subsection{Theoretical implications}

Interestingly, creative thinking in remote collaboration on sensitive or challenging topics, such as infections and death, seems to elicit more of an emotional response than analytical thinking. Emotions are an implicit part of design work, and various emotions, such as fear or happiness, can occur in creative design (Sas and Zhang 2010). Our data suggest that the Brainstorming teams had a higher fluctuation of emotions between DC1 and DC2 in comparison to the Problem Analysis teams. This insight suggests that a Brainstorming method stimulates and channels a designer's emotions, while analytical thinking is a more rational and emotionally neutral method. Future research should focus on characterizing the cognitive, emotional, and social influence of methods on remote team members to enable psychological freedom and safety that is conducive to creativity (Auernhammer \& Hall 2014; Rogers 1954). Creative thinking enabled by Brainstorming process methods can facilitate how remote teams navigate affective conflict. Brainstorming increases emotional responses and might channel the 
team's emotions productively into ideas. This suggestion is related to the findings by Sutton \& Hargadon (1996) and Hinds (2003). However, further research is needed to confirm this proposition.

Remote Brainstorming did not increase the number of ideas post-intervention. This result may be due to the natural tendency to generate ideas using a method like the behavior enabled by Brainstorming in the design challenge pre-intervention. Future research should investigate the moderating effect of previous exposure to group creative methods and expertise.

In practice, design teams utilize both creative and analytical methods to accomplish different design tasks. Future research can look at how both Brainstorming and Problem Analysis methods can work in tandem when applied by expert design teams and their related implications in design team interactions in remote collaboration.

\subsection{Practical implications}

The practical implication of this study is that in a time-bound meeting, discussion on problem characterization precluded discussion for idea generation, resulting in fewer expressed solution ideas. Methods, such as Brainstorming and Five-Whys, should be used judiciously depending on the team's goal. Good design outcomes come from both analytical and creative thinking to understand the problem context, generate many ideas, and critically assess the ideas.

OpenFace, as an observation tool, allowed us to examine participants' emotional states through facial expressions. Knowing which and how design methods impact the emotions of a team, especially when discussing sensitive topics, is essential when coaching and facilitating teams in remote work since viewers are limited in their scope of non-verbal communication.

Our data do not support an immediate effect of improved performance in a remote setting due to a Brainstorming intervention. This finding may run contrary to the practice of short-term design workshops where students or attendees are given a lecture on Brainstorming then apply the method expecting immediate effects. Effective Brainstorming might require expertise, experience, and social and cultural context developed over a longer period of time (Sutton \& Hargadon 1996).

In-person design sessions lend themselves to shared media such as whiteboards, which could help capture and share two-dimensional mind maps amongst team members. In our study, teams brainstormed using only words. Sketches and prototypes enable designers to communicate visually (McKim, 1980). They are limited in remote collaboration since team members cannot all share the same physical sketch. There is an opportunity to mediate the effects of Brainstorming in remote design team collaboration through tools that allow group visual thinking ideation and coordination.

This exploratory study aimed to gather insights on remote collaborations and the use of methods, and their effects on team collaboration. For enabling remote collaborative design, we need to improve our understanding of these effects, their limitations, and benefits to develop methods and communication technology that enables design teams to tackle the complex global design challenges.

\section{ACKNOWLEDGMENTS}

We like to thank the broader designX community, particularly Soh Kim and Dave Miller, for their input and advice.

\section{REFERENCES}

Adams, J. L. (1974). Conceptual blockbusting. Stanford Alumni Association.

Auernhammer, J., \& Hall, H. (2014). Organizational culture in knowledge creation, creativity and innovation: Towards the Freiraum model. Journal of Information Science, 40(2), 154-166.

Baltrusaitis, T., Zadeh, A., Lim, Y. C., \& Morency, L. P. (2018, May). Openface 2.0: Facial behavior analysis toolkit. In 2018 13th IEEE International Conference on Automatic Face \& Gesture Recognition (FG 2018) (pp. 59-66). IEEE.

Chikersal, P., Tomprou, M., Kim, Y. J., Woolley, A. W., \& Dabbish, L. (2017, February). Deep structures of collaboration: physiological correlates of collective intelligence and group satisfaction. In Proceedings of 
the 2017 ACM Conference on Computer Supported Cooperative Work and Social Computing (pp. 873-888).

Ekman, P., \& Friesen, W. V. (1978). Manual for the facial action coding system. Consulting Psychologists Press.

Eris, Ö. (2003). Asking generative design questions: a fundamental cognitive mechanism in design thinking. In DS 31: Proceedings of ICED 03, the 14th International Conference on Engineering Design, Stockholm (pp. 587-588).

Eris, O., Martelaro, N., \& Badke-Schaub, P. (2014). A comparative analysis of multimodal communication during design sketching in co-located and distributed environments. Design Studies, 35(6), 559-592.

Guilford, J. P. (1950). Creativity. American Psychologist, 5(9), 444-454. https://doi.org/https://doiorg.stanford.idm.oclc.org/10.1037/h0063487

Hinds, P. J., \& Bailey, D. E. (2003). Out of sight, out of sync: Understanding conflict in distributed teams. Organization science, 14(6), 615-632.

Ishikawa, K. (1968). Guide to quality control (Japanese): Gemba no QC shuho.

Jung, M. F. (2011). Engineering team performance and emotion: Affective interaction dynamics as indicators of design team performance. Stanford University.

Kumar, V. (2012). 101 design methods: A structured approach for driving innovation in your organization. John Wiley \& Sons.

Lewin, K. (1946). Action research and minority problems. Journal of social issues, 2(4), 34-46.

Liker, J.K., 2004. Toyota way: 14 management principles from the world's greatest manufacturer. McGraw-Hill Education.

Markman, A. (2020), How to Brainstorm - Remotely. Harvard Business Review.

McKim, R. H. (1980). Experiences in visual thinking. Brooks/Cole Publishing Company

McLuhan, M. (1994). Understanding media: The extensions of man. MIT press.

Ohno, T. (1988). Toyota production system: beyond large-scale production. crc Press.

Osborn, A. F. (1953). Applied imagination. New York: Charles Schibner's Son

Sas, C., \& Zhang, C. (2010). Investigating emotions in creative design.

Sirkin, D. M. (2011). Design at a Distance: Tangible Telepresence Using Gesture and Robotics. Stanford University.

Sutton, R. I., \& Hargadon, A. (1996). Brainstorming groups in context: Effectiveness in a product design firm. Administrative science quarterly, 685-718.

Tang, J. C., \& Leifer, L. J. (1988, January). A framework for understanding the workspace activity of design teams. In Proceedings of the 1988 ACM conference on Computer-supported cooperative work (pp. 244-249).

Zwicky, F. (1969). Discovery, invention, research through the morphological approach. The Mamillan Company 